\title{
Análise de registros escritos no âmbito de um processo supervisivo ${ }^{1}$
}

\author{
Teresa N. R. Gonçalves* \\ Joana Campos**
}

\section{Resumo}

No presente texto procura-se contribuir para a discussão dos processos de supervisão e de construção do conhecimento profissional, a partir da apresentação da análise dos pôsteres elaborados pelos professores envolvidos no programa de Supervisão, Acompanhamento e Avaliação do Período Probatório de Professores. Na análise retomaram-se os objetivos da formação em supervisão concebida e implementada no âmbito do programa: a relevância do processo supervisivo; a centralidade da reflexão; a relação com o conhecimento e desenvolvimento profissional. Na discussão dos resultados destaca-se a importância atribuída ao processo supervisivo, reforçando a relevância da dimensão relacional neste processo. Menos expressivos são os resultados relativos à centralidade da reflexão no processo em análise. No que diz respeito ao conhecimento profissional destacou-se o uso predominante das dimensões relativas ao conhecimento do conteúdo, do currículo, didático, pedagógico e reflexivo. A dimensão relativa ao conhecimento científico foi a menos comum.

Palavras-chave: Supervisão. Conhecimento Profissional. Professores

\section{Analysis of written records under a supervision process Abstract}

This paper aims at contributing for the discussions around the processes of supervision and professional knowledge, through the analysis of posters produced by the teachers involved in the first edition of the Teachers' Probation Period in Portugal. We took as a reference for our analysis the aims of the training

1 Os dados apresentados foram recolhidos no âmbito do Programa Supervisão, Acompanhamento e Avaliação do Período Probatório de Professores, desenvolvido no âmbito de um protocolo celebrado entre o Ministério da Educação de Portugal, através da Direcção-Geral dos Recursos Humanos da Educação (DGRHE) e a Universidade de Aveiro, através do Laboratório de Avaliação da Qualidade Educativa (LAQE). Os autores fazem parte da equipa de acompanhamento da primeira implementação do período probatório de professores em Portugal, convidada pelo Ministério da Educação e coordenada pela Universidade de Aveiro. Outros membros da equipa: Nilza Costa (Coordenadora), Maria do Céu Roldão, Idalina Martins, Isabel Candeias, Pedro Reis, Maria Figueiredo, Teresa Leite e Luciana Mesquita

* UIED/FCT/Universidade Nova de Lisboa. E-mail: tprg@fct.unl.pt

** Escola Superior de Educação, Instituto Politécnico de Lisboa CIES/ISCTE-IUL. E-mail: jcampos@eselx.ipl.pt 
program: the relevance of the supervision process; the centrality of reflection and the relation to professional knowledge and development. In the discussion of the findings we highlight: the importance attributed to the supervision process, stressing the relevance of the relational dimension within this process. The findings related to the centrality of reflexivity within the process are less expressive. Concerning professional knowledge we highlight the predominant use of the following dimensions: knowledge about content, curriculum, didactics, pedagogical and reflexive. Scientific knowledge is the least used.

Keywords: Supervision. Professional knowledge. Teachers.

\section{Análisis de registros escrito en el ámbito de un proceso supervisivo Resumen}

El presente texto pretende contribuir con la discusión de los procesos de supervisión y de construcción del conocimiento profesional, a partir de la presentación del análisis de los posters que los profesores participantes produjeron en la primera implementación del período probatorio en Portugal. En dicho análisis se retoman los objetivos de la formación: la importancia del proceso de supervisión, la centralidad de la reflexión y la relación con el conocimiento y desarrollo profesional. En la discusión de los resultados se destaca: la importancia atribuida a la supervisión, subrayando la relevancia de la dimensión relacional. Los resultados relacionados con la centralidad de la reflexión son menos expresivos. Con relación al conocimiento profesional se distingue el uso predominante de las dimensiones relativas al conocimiento del contenido, del currículo, del ámbito didáctico, pedagógico y reflexivo. La dimensión relativa al conocimiento científico ha sido la menos común. Palabras clave: Supervisión. Conocimiento profesional. Profesores.

\section{Supervisão, desenvolvimento profissional e produção de conhecimento}

A análise que no presente artigo se apresenta centrou-se no desenvolvimento do processo supervisivo, ancorado na formação especificamente definida para o desenvolvimento do programa de Supervisão, Acompanhamento e Avaliação do Período Probatório de Professores (apresentado e analisado por Teresa Leite, em texto anterior), pretendendo contribuir para o desenvolvimento profissional dos professores em período probatório.

Como referido no artigo de abertura do presente dossiê (Maria do Céu Roldão, Pedro Reis e Nilza Costa) a formação em supervisão foi concebida e orientada segundo um modelo clínico-humanista, orientado para o desenvolvimento profissional (ALARCÃO; TAVARES, 2003) dos Professores Mentores (PM) e dos Professores em Periodo Probatório (PPP). 0 
programa procurou operacionalizar um conceito de supervisão entendido como ação orientada para o questionamento, a melhoria e a construção do conhecimento profissional. A supervisão é concebida como promotora de uma atitude crítica e reflexiva (REIS, 2008) e, enquanto estrutura de regulação e incremento do desenvolvimento profissional, com possibilidade de uso de diferentes estratégias (ROLDÃO, 2010). Para que resulte num processo efetivamente formativo, a supervisão tem que partir da análise de situações reais do contexto escolar, assentar em processos de diagnóstico, recolha, análise, reflexão, explicitação, estruturação e comunicação dos dados recolhidos e situações vividas que possibilitem e promovam a mudança e melhoria das práticas dos docentes envolvidos e a (re)construção do conhecimento profissional dos docentes (CAMPOS; GONÇALVES, 2010).

No que diz respeito ao conhecimento profissional dos professores, a produção do conhecimento constitui uma das dimensões consideradas como mais débeis (ROLDÃO, $2007,2010)$ uma vez que se encontra pouco enraizada na cultura profissional docente (NÓVOA, 2008; ROLDÃO, 2008) . Nesse sentido, necessita ser promovida e estimulada, na medida em que pode constituir-se como uma das faces mais visiveis da capacidade de produção e participação dos professores na construção do conhecimento sobre a profissão docente e contribuir para ultrapassar a exterioridade existente entre a produção de conhecimento sobre a profissão docente e o exercício da profissão (NÓVOA, 2008).

A relação entre supervisão, desenvolvimento e conhecimento profissional passa pela possibilidade e necessidade de se desenvolver a "[...] capacidade de gerar, gerir e partilhar conhecimento" (ALARCÃO; ROLDÃO, 2008 p. 19) no âmbito de processos supervisivos. Nesse âmbito, o relato e/ou registro, entendido como reflexão sobre um processo de supervisão/formação, e de sua síntese, constitui um instrumento de reestruturação do conhecimento de reflexão e metarreflexão, de natureza textual e científica, sustentado na análise e interpretação dos dados/evidências recolhidos e em situações experienciadas no âmbito de um determinado processo, que se considera fundamental para a promoção do desenvolvimento profissional dos professores e para a sua participação na construção e produção do conhecimento sobre a profissão.

No presente artigo pretende-se analisar o contributo da formação desenvolvida no âmbito do Programa de Supervisão, Apoio e Acompanhamento do Período Probatório para alcançar a finalidade da supervisão. Supervisão definida como estrutura de regulação e incremento do desenvolvimento profissional e como contributo para a construção do conhecimento profissional. Definiu-se como objeto da análise que aqui se apresenta parte dos registros escritos produzidos pelos professores mentores no âmbito do processo de formação - os pôsteres - , relativos à supervisão desenvolvida junto dos professores em período probatório. A pertinência dessa escolha, em termos teóricos e analíticos reside, em parte, no reconhecimento do potencial analítico e reflexivo dos registros escritos no âmbito de processos supervisivos diversos (ALARCÃO; ROLDÃO, 2008); e que tem vindo a ser amplamente discutido, tal como outros estudos têm vindo a demonstrar (DAY, 2001; ALARCÃO; ROLDÃO, 2008). 
Partindo do reconhecimento de que a complexidade e carácter compósito constitui uma das marcas definidoras do conhecimento profissional dos professores (ROLDÃO, 2007 , 2009), a presente análise procurou destacar, sobretudo, a posição dos professores face à produção do conhecimento, e menos o tipo ou natureza do conhecimento manifestado. Sendo que, como acima se referiu, a produção de conhecimento constitui uma das dimensões do conhecimento profissional dos professores consideradas como uma das mais frágeis, considera-se contudo, que ela pode constituir-se como uma das faces mais visiveis da sua capacidade de produção e participação através da definição e implementação dos mecanismos e instrumentos adequados à sua promoção, nomeadamente mecanismos de formação e supervisão. Destaca-se, neste contexto, a importância de que se revestem procedimentos como a construção e elaboração de registros escritos passíveis de serem comunicados e apresentados em reuniões de equipa e fóruns de discussão científica e profissional. A possibilidade e capacidade de produção e discussão de registrosregistros e relatos em contexto académico, traduz assim a integração e participação, ou não, dos professores nesse âmbito da produção.

Na formação dinamizada no âmbito do programa de Supervisão, Acompanhamento e Avaliação do Período Probatório de Professores (apresentada nos seus princípios em artigo anterior, da autoria de Teresa Leite) os professores que frequentaram a formação - professores mentores - foram convidados a produzir um pôr para ser apresentado na última sessão do processo formativo, o seminário final. 0 pôster, resultante da colaboração PM-PPP, constituiu um relato de um episódio de supervisão que considerassem relevante relativamente ao processo e do qual destacassem as mais-valias e limitações dele decorrentes. Esta produção conjunta PM-PPP foi apresentada publicamente no referido seminário final que decorreu em Junho de 2010 na Universidade de Aveiro, o qual constituiu uma oportunidade de fazer o balanço do processo e de analisar e discutir as evidências de progresso comparativamente à situação inicial e aos saberes adquiridos pelos intervenientes (como referido no artigo de abertura por Maria do Céu Roldão, Pedro Reis e Nilza Costa). A escolha desse desafio resultou da pretensão que no âmbito da formação os professores tivessem a oportunidade de processualmente construir um produto final que fosse simultaneamente "transferivel" e "passivel de ser debatido/questionado" (CAMPOS; GONÇALVES, 2010). A concepção, apresentação e discussão em torno de um pôster num encontro público correspondeu, assim, a tal intencionalidade. Ou seja, a possibilidade de se desenvolver a "[...] a capacidade de gerar, gerir e partilhar conhecimento" (ALARCÃO; ROLDÃO, 2008, p. 19).

Na sessão de formação de suporte à produção dos pôsteres, e correspondente brochura, enfatizou-se a diversidade de possibilidades de registrosregistros escritos, sejam as narrativas, as histórias de vida, os diários reflexivos, entre outros (CAMPOS; GONÇALVES, 2010). A importância do seu potencial analítico e reflexivo, como referem Alarcão e Roldão (2008), revela-se no resultado da transição de "registros descritivos" para a produção de "registros analíticos". A potencialidade dessa tran- 
sição traduz-se ainda, segundo Reis (2008) na possibilidade de alteração de formas de pensamento e ação, de modificação de práticas, e promoção de atitude crítica e reflexiva. Tais procedimentos revestem-se de particular relevância se desenvolvidos no âmbito de processos como os de indução, sobretudo se entendidos como etapa de desenvolvimento profissional, como se refere de modo mais aprofundado no artigo de abertura do dossiê (Pedro Reis, Maria do Céu Roldão e Nilza Costa).

Embora tenha resultado de um pedido/estímulo exterior, proveniente da equipa de formação, o percurso proposto permitiu que os professores partissem da seleção de uma situação da sua vivência em contexto profissional que registaram como episódio/incidente. Para a maioria dos professores este exercício inicialmente desenvolveu-se de modo individual, tendo posteriormente passado a uma situação colaborativa. A seleção do episódio, a sua fixação escrita e trabalho conjunto entre professor mentor e professor em período probatório implicou assim que pensassem para quem se dirigia o seu relato e para que tipo de situação, como a discussão e debate público. Tal ação resultou no abandono de um relato de carácter informal passando a assumir-se como uma tomada de decisão relativa ao teor, forma e intencionalidade da ação (GONÇALVES, 2010). Como anteriormente se afirmou:

"A transição entre o relato produzido para ser usado na esfera da ação do professor pelo próprio professor e, num círculo mais alargado, o uso desse relato para a discussão pública entre pares e outros, pode corresponder à transformação de um produto inicialmente considerado rotineiro em formas de saber profissional mais formalizado" (CAMPOS; GONÇALVES, 2010, p. 37).

0 programa de formação estava organizado em 6 sessões, o desafio foi proposto entre a $3^{\text {a }}$ e a $4^{\text {a }}$ sessões de formação, de modo a que os professores mentores num primeiro momento, se focassem na escolha de um episódio ou incidente relativo ao processo de supervisão. Num momento seguinte, na $4^{\text {a }}$ sessão, os professores apresentaram sumariamente os episódios e incidentes escolhidos ao grande grupo. 0 debate em torno do episódio/incidente e as razões das suas escolhas ocuparam parte da sessão, permitindo então a explanação da proposta de elaboração de pôsteres a apresentar no seminário final. A $5^{\mathrm{a}}$ sessão, antes do seminário final ( $6^{\mathrm{a}}$ sessão), foi dedicada à discussão e análise do papel dos r e relatórios no processo de supervisão e como instrumentos de desenvolvimento profissional dos professores.

Os professores mentores (PM) foram apresentando as propostas e ideias que com os respectivos professores em periodo probatório (PPP), consideraram ser as mais relevantes para a apresentação no seminário final. A equipa de formação forneceu uma proposta de estrutura para a elaboração dos pôsteres, de modo a apoiar a sua elaboração e posterior apresentação. A estrutura apresentada procurou distribuir genericamente os campos de informação, distinguindo: a apresentação do pôster - Título e Autores; a apresentação do 
episódio/incidente - Contextualização do episódio no periodo probatório, e Articulação do episódio com o Plano Individual de Trabalho (PIT) do PPP -, apresentação da análise desenvolvida em torno do episódio/incidente - Avaliação do episódio, e Reflexão Global; e no final, as Referências bibliográficas. 0 layout do pôster foi disponibilizado digitalmente, por forma a uniformizar as apresentações no que aos aspectos formais diz respeito.

\section{Procedimentos Metodológicos}

A análise realizada foi orientada pelas dimensões e princípios que presidiram à organização do programa de Supervisão, Acompanhamento e Avaliação do Período Probatório pela equipa responsável: a) a ideia de um processo de desenvolvimento profissional orientado para a melhoria do desempenho nas diferentes áreas associadas ao trabalho do professor - científicas, pedagógico-didáticas, culturais, organizacionais e sociais (ROLDÃO, 2010); b) sustentado num processo supervisivo organizado em torno do estudo de situações reais, fundamentado em "processos de diagnóstico recolha, análise, reflexão, explicitação, estruturação e comunicação dos dados recolhidos e situações vividas" orientado para a melhoria das práticas e para a (re)construção do conhecimento profissional, sustentado em mecanismos de natureza reflexiva e sistemática (CAMPOS; GONÇALVES, 2010, p. 7); c) o reconhecimento da importância do registro escrito nos processos supervisivos considerando o seu potencial analítico e reflexivo. Tendo em conta os princípios referidos, o da presente análise foi o de compreender de que forma e em que medida a orientação e objetivos do processo se refletem nos registros produzidos pelos seus principais intervenientes - PM e PPP -, neste caso específico nos pôsteres.

Para a presente análise considerou-se a totalidade dos pôsteres apresentados no seminário final, num total de 75 pôsteres. Os 75 deles elaborados nas sessões de formação, correspondem aos grupos de formação, resultando na distribuição territorial apresentada no quadro seguinte.

Quadro 1: Número de pôsteres por região (grupo de formação).

\begin{tabular}{|c|c|}
\hline Região & Número de pôsteres \\
\hline Lisboa & 20 \\
\hline Aveiro & 18 \\
\hline Braga & 15 \\
\hline Évora & 12 \\
\hline Faro & 10 \\
\hline
\end{tabular}

Fonte: A autora (2012).

Relativamente à autoria dos 75 pôsteres, na sua maioria houve 2 autores, correspondendo em grande medida a pares compostos por Professor Mentor (PM) e Professor em Período Probatório (PPP). 
Quadro 2: Número de autores por pôsteres.

\begin{tabular}{|c|c|}
\hline Número de Autores & Número de pôsteres \\
\hline 1 autor & 6 \\
\hline 2 autores & 63 \\
\hline 3 autores & 6 \\
\hline
\end{tabular}

Fonte: A autora (2012).

\section{Análise e discussão dos resultados}

Analiticamente definiram-se três eixos, um primeiro relativo à caracterização dos episódios selecionados pelos professores autores dos pôsteres, um segundo relativo à supervisão e cultura profissional, e um terceiro que se prende essencialmente com os aspectos formais de elaboração e apresentação dos pôsteres, concretamente, ao uso de referenciais bibliográficos e imagéticos.

\section{Análise dos episódios: as temáticas dos Pôsteres}

Para o primeiro eixo analítico, consideraram-se analiticamente dimensões relativas às situações descritas, isto é, relativamente aos episódios selecionados pelos professores para o desenvolvimento do exercício proposto. As dimensões definidas referem-se essencialmente à natureza do episódio selecionado, ao contexto do episódio, à implicação dos professores/autores no episódio e ainda, a avaliação do episódio.

A distribuição dos pôsteres por áreas temáticas permite compreender que há uma clara concentração de temas relativos ao trabalho docente em sala de aula, seguido do trabalho entre docentes e situações de supervisão. Com frequências menos elevadas encontram-se as temáticas relativas ao trabalho a nivel de escola, sendo a relação com o exterior a categoria mais residual.

Quadro 3: Distribuição de temáticas tratadas nos pôsteres.

\begin{tabular}{l|l|l|l}
\hline \multirow{2}{*}{ Temáticas } & \multicolumn{2}{|l|}{ Subtemáticas } & Freq. \\
\hline \multirow{4}{*}{$\begin{array}{l}\text { Integração/inclusão de } \\
\text { em Sala de aula }\end{array}$} & alunos estrangeiros & 1 \\
\cline { 3 - 4 } 28 & & $\begin{array}{l}\text { alunos com deficiência/necessidades } \\
\text { educativas especiais }\end{array}$ & 8 \\
\cline { 3 - 4 } & \multirow{4}{*}{$\begin{array}{l}\text { Elunos problemáticos /Indisciplina } \\
\text { Estratégias de ensino }\end{array}$} & 4 \\
\cline { 3 - 4 } & & Gerais & 4 \\
\cline { 3 - 4 } & & Trabalho de grupo & 3 \\
\cline { 3 - 4 } & & Dramatização interação oral & 2 \\
\cline { 3 - 4 } & & Ensino de língua estrangeira & 5 \\
\cline { 3 - 4 } & & TIC & 1 \\
\hline
\end{tabular}

(Continuação) 
(Continuação)

\begin{tabular}{|c|c|c|}
\hline \multirow{2}{*}{$\begin{array}{l}\text { Trabalho docente } \\
\text { (não-letivo) } \\
19\end{array}$} & Trabalho colaborativo & 14 \\
\hline & Planificação & 5 \\
\hline \multirow{2}{*}{$\begin{array}{l}\text { Escola } \\
9\end{array}$} & Resolução de problemas & 6 \\
\hline & Dinamização de atividades & 3 \\
\hline \multirow{2}{*}{$\begin{array}{l}\text { Relação com o ex- } \\
\text { terior } \\
5\end{array}$} & Visitas de estudo & 3 \\
\hline & Intercâmbios & 2 \\
\hline \multirow{2}{*}{$\begin{array}{l}\text { Supervisão/inicia- } \\
\text { ção profissional } \\
14\end{array}$} & Integração de docentes & 3 \\
\hline & Trabalho conjunto entre PM e PPP & 11 \\
\hline \multicolumn{2}{|l|}{ Total } & 75 \\
\hline
\end{tabular}

Fonte: A autora (2012).

A categoria relativa ao Trabalho Docente em Sala de Aula é a que reúne o maior número de pôsteres, distinguindo-se entre os que se ocupam de processos de inclusão/ integração de alunos (com Necessidades Educativas Especiais, alunos estrangeiros e ainda, alunos com problemas de indisciplina) de outros que se dirigem essencialmente a situações de desenvolvimento de estratégias de ensino e aprendizagem. Relativamente às estratégias de ensino desenvolvidas em sala de aula, sublinha-se a distribuição entre estratégias gerais de melhoria do ensino e aprendizagem de outras mais especificas, que se prendem com ensino da língua estrangeira, TIC e metodologias diversificadas, como trabalho de grupo, recurso a dramatizações entre outros exemplos.

Nos pôsteres posicionados na categoria relativa a situações de trabalho docente não letivo, o trabalho entre professores assume posição de destaque, sendo mais significativo o que se prende com trabalho colaborativo de equipa; havendo, contudo, situações bem distintas, como, por exemplo, duas situações relativas a equipas de docentes provenientes de escolas diferentes. A maioria dos exemplos apresentados prende-se com trabalho de equipas da mesma escola, que se organizam em torno da elaboração de projetos como o projeto curricular de escola e/ou de agrupamento de escolas, situações do trabalho de grupo disciplinar e/ou departamento, de conselho de turma e direção de turma; sejam ainda processos de desenvolvimento curricular, como o exemplo da implementação de novos programas, entre outras situações. Um subgrupo, prende-se essencialmente com o trabalho desenvolvido em torno da preparação e dinamização de processos de formação, num caso de docentes, e noutro, de encarregados de educação. No mesmo âmbito, mas mais distanciados, 2 pôsteres dão conta de experiências de colaboração entre professores de diferentes escolas, 1 sobre 0 trabalho de uma equipa multidisciplinar, e outro sobre trabalho a nivel do grupo disciplinar e de departamento. Ainda no que diz respeito ao trabalho docente, à preparação de situações letivas assume particular destaque, com a planificação a ocupar tematicamente 5 pôsteres. 
Os episódios reunidos na categoria Escola são relativos a situações de intervenção a um nível organizacional mais alargado. Há 2 exemplos de trabalho desenvolvido em torno da melhoria de condições de salas de aula, como resultado do diagnóstico elaborado pelos professores em período probatório no âmbito do processo formativo. Outros episódios dirigem-se à escola, mas em sentido lato, considerando a comunidade escolar, tendo como exemplos a implementação de projetos de inclusão, em 3 pôsteres, relativo ao processo de informatização da escola, num único exemplo, e ainda outros que, mais genericamente, se ocupam da dinamização de atividades dirigidas à escola, como: dias abertos à comunidade, comemorações desportivas entre outros exemplos. Por fim, uma última categoria que agrega os episódios que se enquadram em situações de relação da escola com o exterior, como a organização e dinamização das visitas de estudo, e intercâmbio com outras escolas, nos dois casos, estrangeiras.

Na categoria seguinte reuniram-se os pôsteres relativos a situações em que o pano de fundo se prende com o processo supervisivo desenvolvido no âmbito do programa. Assim, num primeiro grupo, encontram-se os pôsteres que se ocupam da integração de docentes, seja por serem recém-chegados à escola, à equipa de um projeto, seja ainda pelo apoio do Professor Mentor na integração de um projeto do PPP na escola.

No âmbito das situações de supervisão são mais frequentes as situações relativas ao trabalho conjunto entre PM e PPP, seja de apoio do PM ao PPP, em aulas assistidas, seja na elaboração do diagnóstico, seja ainda na reflexão e avaliação em torno do trabalho desenvolvido. 0 trabalho conjunto é também a situação eleita noutros 3 pôsteres que se debruçam sobre episódios relativos à construção de instrumentos de avaliação das aprendizagens dos alunos.

A análise temática dos pôsteres permite afirmar que a maioria das temáticas escolhidas se focam num dos aspectos centrais da profissão: a docência, nas suas dimensões de preparação e de ação junto dos alunos. Por outro lado, o lugar ocupado pelas temáticas relativas ao centro do programa/formação é também significativo. Pode afirmar-se que supervisão e docência assumem uma preponderância significativa na escolha dos episódios, o que se compreende se considerarmos o programa como momento de desenvolvimento profissional para professores em início de carreira (indução). Embora considerando que no grupo se encontram também professores com alguma experiência, não deixa de ser interessante notar que "usaram" o programa para efetivamente desenvolver práticas colaborativas e iniciar/fortalecer dinâmicas de supervisão horizontal.

\section{Natureza dos episódios selecionados}

Uma primeira dimensão diz respeito à natureza do episódio relativamente ao processo de indução e supervisão vivido no âmbito do programa em estudo. Procurou-se, assim, distinguir entre os episódios que dizem respeito ao quotidiano escolar, identificados como situações internas, de outras de carácter extraordinário e que decorrem do processo de indução/supervisão em curso, consideradas analiticamente 
como externas. Relativamente à natureza das situações/episódios descritos, no que diz respeito ao processo, isto é, relativamente ao período probatório, a maioria refere-se a situações externas, provocadas no âmbito do programa. Tais situações relacionam-se tanto com os objetivos e exigências do programa, relativamente ao desempenho e avaliação do Professor em Período Probatório, como com as dificuldades e necessidades identificadas na elaboração do Plano Individual de Trabalho (exigido pelo Programa). Alguns exemplos estão relacionados com a inexperiência e receios dos professores em Período Probatório PPP, como alguns referem: "Na fase destinada ao diagnóstico, identificou-se algum receio da parte da professora em período probatório em realizar trabalhos de grupo" (E10); "A PPP está pela primeira vez a leccionar na escola, o PM está no quadro da escola há 27 anos e a direção da escola procura estar atenta a todos os problemas e conflitos que surjam diariamente"(F9).

Outros episódios são despoletados pela análise diagnóstica desenvolvida no âmbito de Plano Individual de Trabalho ou da observação de aulas, como explicam :

"O episódio ocorreu numa turma de $10^{\circ}$ ano do curso profissional de técnico de animação sociocultural. A turma evidencia um comportamento problemático, por integrar alunos muito pouco motivados, desinteressados e sem hábitos de estudo, oriundos dos chamados currículos alternativos. A grande motivação dos alunos, mesmo em contexto de sala de aula, é pela navegação na internet por sites não relacionados com os conteúdos programáticos, nomeadamente jogos e comunidades sociais como é o caso do facebook" (F8).

E ainda outras situações descritas ligadas às exigências do processo do periodo probatório, como o desenvolvimento de atividades constantes nos projetos curriculares de escola e/ou de turma, com diversos exemplos, destacando-se para ilustração as apresentações de alguns dos episódios: "Este episódio surge da necessidade de a professora em período probatório contribuir para o desenvolvimento de uma atividade constante do projeto curricular de agrupamento e no projeto curricular de turma" (B6)

Outros exemplos prendem-se com a situação em que o processo vivido no âmbito do Período Probatório foi entendido como oportunidade para estabelecimento de parcerias pedagógicas, como dão conta alguns dos autores: "Para trabalhar estes conteúdos, desenvolveram-se aulas em regime de parceria pedagógica PPP (PM - estudo estatístico. (...) Este trabalho partilhado tem sido útil pelas reflexões e troca de experiências" (L2)

Existem outros episódios que se prendem com situações classificadas como sendo de natureza interna, embora menos representativos que os anteriores, apenas 17 pôsteres dos 75. Dessas situações, parte decorre de dinâmicas e necessidades da própria escola, como o exemplo de uma escola em Braga: "A escola EB 2,3 foi selecionada pela Direção 
Regional Educativa Norte e pela Direção-Geral do Desenvolvimento e Inovação Curricular, para a implementação de um Novo Programa de Espanhol para o $5^{\circ}$ ano, numa turma piloto [...] o professor em período probatório colaborou nesta experiência" (B11), ou outra na região de Faro: "A escola tem uma sala de multideficiência e na medida do possivel tenta integrar alguns alunos em aulas das turmas de $5^{\circ}$ ano" (F6).

Outros exemplos de episódios internos resultam de trabalho desenvolvido no âmbito dos grupos disciplinares, como os exemplos seguintes: "Anualmente o departamento de línguas é chamado a colaborar com a biblioteca escolar/centro de recursos escolares na Semana da Leitura" (A2), ou noutro caso, com "A visita de estudo a Sevilha surge no âmbito do contexto do Período Probatório como um episódio de supervisão pedagógica [...] A visita de estudo foi planificada pelas docentes da Área Disciplinar de Espanhol, tendo a docente em Período Probatório assumindo um papel preponderante nos contactos estabelecidos com a agência de viagens contratada, os guias, a direção da escola e os encarregados de educação" (E11).

Por fim, os exemplos que dizem respeito, mais especificamente, à leccionação de uma determinada disciplina e que se ocupam da "concepção e implementação de estratégias que contribuam para as finalidades do currículo de Espanhol" (A10), como num dos casos, ou das necessidades dos alunos, como noutros em que "0 episódio centra-se na revisão das medidas educativas de uma aluna, cuja resposta educativa escolar está desajustada às expectativas futuras e reais capacidades individuais" (A9).

Outra linha categorial prende-se com a natureza da situação, procurando-se distinguir-se as situações relativas à docência de outras. A maioria dos episódios estão relacionados com a docência e, em particular, com aspectos relativos a situações de ensino-aprendizagem em contexto de sala de aula ou na escola, 61 em 75 episódios. Como exemplos ilustrativos destacam-se a planificação e organização do trabalho docente, como, por exemplo, os procedimentos relativos a "operacionalizar nas aulas as seguintes formas de correção de textos: [...]" (B4); "O tema do episódio escolhido esteve sempre presente nas discussões de trabalho, ao longo do processo, principalmente na realização do trabalho teórico - construir e conceber um plano para uma turma/grupo de alunos e uma planificação de uma unidade de aprendizagem escolhida dentro do plano" (L4).

0 trabalho colaborativo, no sentido de melhorar o trabalho docente e as aprendizagens dos alunos, encontra-se em 3 pôsteres, como no caso de Aveiro que se centra no "trabalho colaborativo entre os diferentes profissionais que interagem com o aluno" (A4).

Apenas 14 dos episódios estão relacionados com outros aspectos como o exercício de cargos (como o de diretor de turma) no exemplo de um pôster de Aveiro, "Na sequência da atribuição do cargo de diretora de turma de um curso de educação e formação à professora em período probatório, tornou-se necessária a partilha de 
experiências e materiais entre esta e a professora mentora" (A1), e ainda episódios relativos ao trabalho colaborativo, em 4 casos, à relação com a comunidade escolar e a participação em atividades da escola, em 3 casos, como o exemplo descrito num dos pôsteres de Faro: "O episódio descrito ocorreu, por um lado, por a PPP ter consciência de que tinha um problema e que a resolução, absoluta ou relativa do mesmo deveria passar pela colaboração mútua entre todos os elementos do conselho de turma (...) Esta consciência está claramente plasmada no PIT da PPP, inscrita na área de desenvolvimento profissional, colaboração com outros docentes" (F2).

Por fim procurou-se caracterizar os episódios relativamente à sua regularidade, distinguindo-se as situações efetivamente episódicas, de carácter extraordinário, de outras situações que são rotineiras e generalizadas na organização e vivência escolares. Relativamente à regularidade face ao quotidiano escolar, a maior parte dos episódios retratados e analisados constituem episódios extraordinários, embora exista um número significativo (34 em 75) relativos a episódios rotineiros ou generalizados. A maior parte dos episódios extraordinários relacionam-se com atividades dinamizadas no âmbito da turma ou da escola, como a "realização de duas ações de sensibilização dirigidas à comunidade educativa [sobre a deficiência visual]" (B1), em Braga, ou visitas de estudo, tanto em Braga como em Évora.

\section{Contextos dos Episódios}

$\mathrm{Na}$ análise em torno dos contextos dos episódios descritos nos pôsteres distinguiram-se as situações que ocorrem em sala de aula ou em situação letiva, na escola ou fora da escola. Nas situações relativas ao exterior da escola, procurou-se ainda destrinçar entre um exterior considerado como comunidade próxima, designadamente junto de parceiros da escola, de um exterior mais distanciado e indiferenciado.

As situações descritas ocorrem principalmente em contexto de sala de aula ou situação letiva, com 45 referências. Os restantes episódios são relativos a contextos situados no exterior da escola, sendo 7 relacionados com a comunidade próxima, como o caso em que "0 professor mentor e o professor em período probatório desenvolveram assim um projeto de reabilitação que foi apresentado à empresa que gere as construções escolares [...]" (B9) e 2 com situações contextualmente indiferenciadas.

\section{Implicação dos professores autores no episódio}

A terceira dimensão procurou visibilizar a implicação dos autores do pôster na ação descrita no episódio, considerando-se a implicação direta na ação ou sem implicação direta na ação. A maioria dos autores (PPP e PM) estava implicado na ação, com 64 referências, tanto ao nivel da concepção, como do acompanhamento, implementação e avaliação. São ilustrações disso os casos em que "o professor em período probatório e o professor mentor conceberam, propuseram aos alunos 
e acompanharam tarefas que incidiram sobre a divulgação das cultura e língua hispanas" (B5); ou "0 professor mentor (PM) colaborou e acompanhou as fases de concepção, operacionalização e avaliação das estratégias e da seleção dos recursos didáticos necessários à ação." (B6), e ainda em que "A Professora Mentora e a Professora em Período Probatório [...] participaram de forma ativa na organização e execução da iniciativa" (A6). Embora nem sempre seja clara a natureza da implicação, como se pode ler nas ilustrações apresentadas, noutros casos não existem dados que permitam identificar a implicação na ação dos professores autores, principalmente no que diz respeito à implicação do Professor Mentor.

\section{Modalidades e Instrumentos de Avaliação}

No que diz respeito à avaliação do episódio em 57 dos 75 pôsteres analisados existe referência aos instrumentos utilizados para a avaliação dos pôsteres, em 18 não existe qualquer referência nem a instrumentos nem ao que foi avaliado e/ou alcançado. Dos instrumentos referidos, destacam-se os instrumentos centrados nos alunos - como autoavaliação, como se pode ler no exemplo: "[...] o facto de existir com frequência autoavaliação para os alunos - baseado na ficha de autoavaliação, ficha formativa, ficha diagnóentre outras - e para a professora também, na consequente revisão da planificação veio completar a sequência de aprendizagens em curso, e reforçar as planificações seguintes; é a colega que me afirma, que, na verdade, a autoavaliação dos alunos dá-Ihe mais tranquilidade - quando tem de avaliar - porque tem dados mais concretos e específicos, e também, porque essa avaliação já foi partilhada e discutida com os alunos, levando-os a ter uma melhor compreensão dos sistema de avaliação, e a criar o hábito de se autocriticarem, de reformularem o seu estudo e de reforçar os pontos mais fracos, e a envolverem-se mais e melhor no seu próprio percurso de aprendizagem" (L11). Outros instrumentos identificados prendem-se com a verificação de aprendizagem e da compreensão dos alunos, em 6 episódios, como os inquéritos por questionário e grelhas entre outros, como se pode ler nos exemplos apresentados: "Avaliação do desempenho dos alunos através de uma grelha específica incidindo sobretudo sobre questões de fluência, prosódia e expressividade dramática" (B14) e "questionário para obtenção de feedback do trabalho realizado por PPP e PM" (B8). Outros instrumentos identificados relacionam-se mais particularmente com a ação docente, novamente com referência a questionários, como ilustração de um dos casos em Lisboa: "As dinâmicas relacionais desenvolvidas neste âmbito foram objeto de avaliação final, através de inquérito aos docentes do conselho de turma" (L7); as reflexões, em 8 casos, como ilustra o pôster Aveiro: "o PPP e o PM realizaram reflexões conjuntas para analisarem a qualidade dos processos de ensino e de aprendizagem" (A6); a observação, em 10 situações, como se ilustra num dos pôsteres de Faro: "Os critérios e instrumentos utilizados para a avaliação do episódio foram as grelhas de observação definidas pela escola, nas reuniões prévias às aulas observadas e o feedback construtivo realizado entre a PPP e a PM após a observação" (F3). 
Alguns casos, os instrumentos utilizados são diversificados, como em 8 dos pôsteres, como exemplo que inclui análise documental, o recursos a "Atas, relatórios de avaliação, questionário" (A11). De modo mais residual referenciam indicadores de avaliação, mas sem que se articulem com os instrumentos, apenas em 8 casos.

No que se refere ao primeiro eixo de análise destaca-se que o periodo probatório desencadeou uma série de situações que não teriam provavelmente existido ou sido fomentadas se não fosse no seu âmbito. Estas situações contribuiram não só para o desenvolvimento profissional dos PPP dos do PM, como ainda em alguns casos, influenciaram e se refletiram na dinâmica da escola a vários níveis - departamentos e grupos disciplinares, órgãos de gestão intermédia e de topo e restante comunidade educativa, tanto pela dinamização e participação do PPP em atividades da escola como pela promoção de trabalho colaborativo e interdisciplinar e mesmo pela articulação e parceria com outras escolas. Os episódios descritos remetem para diferentes niveis de decisão curricular (LEITE, 2010) situando-se tanto no nível de decisão individual nas situações relacionadas com situações de ensino/aprendizagem (abordagem de conteúdos de aprendizagem, programação e sequencia das atividades, organização da aprendizagem, diferenciação curricular) como ao nível grupal no que diz respeito à relação com as estruturas de gestão intermédia e ao trabalho colaborativo; ou mesmo, embora em menor grau, ao nível institucional no que se refere à relação com a comunidade, o envolvimento nas atividades institucionais e o desempenho de cargos. Outro aspecto que nos parece relevante é o contributo do PP para o desenvolvimento de práticas de avaliação sustentadas em evidências recolhidas através de instrumentos diversificados. Mesmo na ausência de referências aos instrumentos, parece existir uma preocupação com a definição de indicadores que permitam avaliar o sucesso da ação.

\section{Supervisão e cultura profissional}

0 segundo eixo definido centra-se numa análise mais substantiva dos conteúdos dos pôsteres apresentados relativamente ao processo de supervisão em análise. As dimensões analíticas definidas referem-se à natureza da relação estabelecida entre PM e PPP e à centralidade conferida à reflexão no processo supervisivo.

\section{Relação entre professor mentor e professor em período probatório}

A relação entre professor mentor e professor em periodo probatório ocupa a primeira dimensão analítica, distinguindo-se aqui duas categorias. Uma primeira referente a uma relação de colaboração de natureza marcadamente expressiva, e uma segunda, de orientação mais técnica, de natureza instrumental. Para a primeira procurou-se ainda subcategorizar de forma a distinguir as situações de maior proximidade, de apoio e acompanhamento, de outras relativas ao esclarecimento e orientação. Quanto à segunda, e no que se prende com colaboração de natureza 
mais técnica, a distinção entre a colaboração nos procedimentos relativos à avaliação de desempenho, de outros desenvolvidos em torno de um questionamento crítico.

0 sentido da relação entre professor mentor e professor mentorado é entendida como uma colaboração no sentido relacional expressivo, principalmente no que se refere ao apoio e acompanhamento da parte do PM, em 8, com 45 referências, das quais se apresentam alguns exemplos: "0 professor mentor acompanhou o desenvolvimento das tarefas inerentes à ação do PPP" (B11); "A avaliação das ações de formação realizadas teve a participação de todos os intervenientes: o PM no seu papel de supervisão e no papel de formando, o próprio PPP (autoavaliação) e os professores formandos" (L10); "a ação da professora mentora centrou-se no apoio e acompanhamento da PPP" (B12).

Em 5 pôsteres as referências refletem o trabalho conjunto desenvolvido entre PPP e PM, embora de forma menos expressiva, como esclarecimento e orientação, tanto no que se refere à orientação do PM na planificação e preparação da situação letiva em 4 pôsteres, como no que se refere à sugestão por parte do PM de estratégias específicas, noutros 4 pôsteres. Os exemplos ilustrativos dão conta da diversidade de situações identificadas: "orientar e enriquecer a reflexão sobre essas mesmas práticas" (B10) ; "A PM assumiu um papel de orientadora das atividades de simulação" (B14); "A ajuda do PM ao PPP, na preparação das aulas em que os alunos da sala de multideficiência são integrados, nomeadamente a preparação dos alunos das turmas em que os alunos participam" (F6).

A relação entre professor mentor e mentorado também é entendida na sua vertente técnico-instrumental, principalmente no que diz respeito à avaliação de desempenho com 45 referências, como se lê na ilustração escolhida, "foi nossa opção apresentar esta episódio no sentido de evidenciar a relevância educativa subjacente à observação de aulas" (A18).

A análise conjunta de situações de ensino previamente planificadas ou da situação observada é frequentemente referida, como, por exemplo, em situações em que "O papel do professor mentor foi, neste caso, o de ajudar o PPP a refletir sobre as potencialidades das WebQuests,.." (E7), ou quando consideram que "À PM cabe o papel de acompanhar e de aconselhar, sugerindo algumas estratégias que poderão ser úteis para a PPP, como, por exemplo, sentar aqueles alunos junto dos que não têm dificuldades e que poderão ajudá-Ios no dia a dia" (F3).

A dimensão que reúne as situações de questionamento crítico, presente em 19 dos pôsteres, refere-se principalmente às situações de questionamento do desempenho docente, como neste exemplo: "Os diferentes intervenientes no processo educativo da aluna consideram que a presente resposta educativa está completamente desajustada. (...) considerámos que seria pertinente reconhecer as más opções tomadas no 
passado e tentar recentrar o seu percurso numa resposta mais adequada..." (A9). As questões relativas à articulação à interdisciplinaridade ocupam igualmente posição nesta categoria, com exemplos como o descrito neste caso de Faro "Nessa altura, a PM incentiva a PPP a colocar a questão aos outros colegas. Mas afinal como é que se faz a articulação? Depois deste tempo ainda não entendi como posso articular os conteúdos de espanhol com as outras disciplinas. Sorrisos de assentimentos e constatação assumida de que esta é uma prática que nos coloca muitas dificuldades" (F2). Importa referir que, nesta categoria, existem muitos casos em que foram assinalados para o mesmo pôster diversos sentidos atribuídos à relação mentor/mentorado. A descrição e análise das situações reflete frequentemente a atribuição em simultâneo de um sentido relacional expressivo e de um sentido técnico-instrumental.

\section{0 uso da reflexão}

A segunda dimensão diz respeito à centralidade conferida à reflexão, distinguindo-se quatro categorias relativas ao centro da reflexão: uma no diagnóstico de desempenho docente, outra no planeamento de processos de melhoria de desempenho; outra na problematização do exercício profissional e, por fim, na autonomia e tomada de decisão na resolução de problemas. No que se refere à reflexão centrada no desempenho profissional, a maioria dos episódios situam-se no planeamento de processos de melhoria do desempenho. Estes processos são de natureza muito diversa, como planificação de atividades extracurriculares (p. ex. visitas de estudo) ou de unidades curriculares, de intercâmbio com outras escolas, como no caso de "A colaboração entre as PM e as PPP das duas escolas permitiu a realização e discussão de tarefas de ensino, a concepção e implementação de estratégias de trabalho, bem como a definição conjunto de procedimentos e instrumentos de avaliação" (A8). Outros exemplos prendem-se com trabalho colaborativo, como o descrito no pôster de Braga: "Este projeto foi também uma oportunidade para a PPP [...] refletir de forma partilhada com o PM e os pares do grupo disciplinar" (B11).

Existem também algumas referências ao diagnóstico do desempenho docente que se relacionam com o diagnóstico de dificuldades ou necessidades associadas à iniciação profissional da PPP: "O episódio insere-se na área de desenvolvimento relativa ao exercício de cargos que, por inexperiência da PPP, carecia de apoio e melhoria" (A1), ou no caso de Lisboa em que "A problemática da socialização do professor foi entendida como primordial, já que a escola é um local de socializações variadas. 0 ator professor em periodo probatório tinha chegado a uma nova escola..." (L4). As necessidades ou dificuldades detectadas na própria escola ou grupo disciplinar também constituem referências para a presente categoria, com situações como "A opção pela realização de duas ações de sensibilização dirigidas à comunidade educativa resultou da constatação prévia da existência de barreiras ao nivel das ações e condutas necessárias para estabelecer com os alunos cegos interações básicas e complexas, de maneira contextual e socialmente adequada." (B1). Em menor número, com apenas 13 referências, os casos relativos à autonomia e 
tomada de decisão na resolução de problemas, entendidos aqui como episódios que provocaram ou operaram alguma mudança relativa a uma situação pré-existente tanto no que diz respeito à escola e comunidade educativa, principalmente no que se refere ao trabalho colaborativo e interdisciplinar, como exemplos: "Renovar as dinâmicas de funcionamento do grupo disciplinar e do departamento de línguas, aprofundando práticas colaborativas" (A11), ou a sala de aula "[...] gerou-se e consolidou-se na escola o princípio de que o período probatório teria de ser um processo dinâmico, ativo e capaz de criar contaminações positivas, envolvendo para tal diversos atores. Assim, o PM e o PPP assumiram um papel interventivo face à problemática diagnosticada na sequência de um trabalho prévio de reflexão e pesquisa, apostaram numa dinâmica colaborativa, visando à criação do referido recurso, o qual foi utilizado, com contexto de sala de aula, pelos docentes da turma e regularmente foi objeto de reflexão/análise por todos os envolvidos" (L7).

Apenas 5 referências relativas à problematização do exercício profissional centram-se no contributo do trabalho colaborativo e na articulação interdisciplinar para o desenvolvimento profissional do Professor em Período Probatório, como no exemplo (A4) "Não obstante, como a própria PPP referiu, ainda existirem alguns aspectos nesta área, que carecem de melhoria [no âmbito da Avaliação Pedagógica Especializada]" (A4); na importância da reflexão sobre as práticas, "O episódio originou mudanças de estratégias [...], possibilitou a reflexão conjunta, o trabalho colaborativo..." (A17); e ainda, na problematização de alguns conceitos como a "escola para todos" (E3) ou o conceito de articulação (F2).

No âmbito da supervisão e desempenho profissional - eixo 2 - a colaboração relacional expressiva e a colaboração técnico-instrumental surgem equiparadas. A centralidade da reflexão no desempenho profissional parece assumir particular relevância no que diz respeito ao diagnóstico do desempenho docente e ao planeamento de processos de melhoria de desempenho, no entanto, é bastante menos significativa no que diz respeito à problematização do exercício profissional ou mesmo à autonomia e tomada de decisão na resolução de problemas. Algumas questões que podem ser colocadas neste ponto relacionam-se com os seguintes aspectos: este facto pode ser atribuído à natureza, organização e implementação do PP ou a aspectos relacionados com a cultura profissional docente? Como podem processos da natureza do PP ser pensados lorganizados de forma a fomentarem um exercício mais crítico, problematizador e autónomo da atividade docente no que se refere aos professores em início de carreira?

\section{0 uso de referenciais imagéticos e bibliográficos}

0 terceiro eixo engloba aspectos de natureza formal, e que se prendem com o uso dos referenciais imagéticos, procurando distinguir-se as imagens recolhidas em situação, na escola e/ou no contexto, de outras selecionadas entre bases e bancos de imagens, usadas como ilustração. A mobilização de referenciais bibliográficos constitui igualmente indi- 
cador de analise, procurando ler-se o tipo de uso na posição das referências nos pôsteres, distinguindo-se entre os que usam referências no corpo do texto dos que apresentam referências apenas no final, na seção da bibliografia. Por fim, a natureza das referências bibliográficas apresentadas, isto é, procurando distinguir entre as de carácter específico, relativas à problemática em discussão, e as de carácter geral, no caso educacional.

A maioria dos autores utiliza imagens recolhidas no curso da situação descrita, 41 em 75 pôsteres, apenas 19 utilizam imagens selecionadas entre outras como ilustração, 12 utilizam os dois tipos de imagem e só 1 não utiliza imagens.

As referências bibliográficas aparecem maioritariamente apenas na bibliografia final, 53 em 75 pôsteres. Em 10 pôsteres as referências aparecem tanto no corpo do texto como na bibliografia final, 3 não têm qualquer referência bibliográfica e 1 tem referências apenas no corpo do texto. Quanto à natureza da bibliografia utilizada, o uso é distribuido entre bibliografia especifica sobre a problemática do episódio, em 39 casos, e de bibliografia geral de carácter educacional, com 33 casos. Uma grande parte das referências na bibliografia são relativas à apresentação do Plano Individual de Trabalho, aos projetos curriculares e aos decretos de lei identificados.

No que se refere ao eixo 3, é de salientar que a referenciação maioritária da bibliografia no final do texto e não no corpo do texto levanta algumas questões relativamente ao uso que os docentes fazem da bibliografia para sustentarem as suas decisões, fundamentarem a sua prática e justificarem a sua análise dos episódios descritos. Algumas questões podem ser colocadas relativamente a este ponto: Porque é que a bibliografia não é mobilizada para a análise da situação? 0 que é que este dado representa relativamente ao uso da bibliografia científica e às perspectivas subjacentes sobre o seu papel na análise de situações profissionais?

\section{Conclusões}

Os resultados que emergem da nossa análise, retomando os objetivos da formação, são susceptiveis de ser pensados tendo em conta três aspectos centrais do período probatório: 1) a relevância do processo supervisivo; 2) a centralidade da reflexão; 3) a relação com o conhecimento e desenvolvimento profissional.

A sua análise permitiu identificar elementos definidores de práticas de supervisão tal como definidas por Roldão (2010), relativos à sua finalidade de apoio e regulação do desenvolvimento profissional, através da utilização de diferentes estratégias de supervisão, como o feedback, o apoio, as sugestões e reflexões, os esclarecimentos que estão presentes no relato e a análise das diversas situações descritas pelos professores em período probatório e pelos mentores. A natureza do processo supervisivo, no que diz respeito à relação entre mentores e professores em período probatório, manifesta-se tanto na sua dimensão relacional expressiva como na sua dimensão técnico-instrumental. A dimensão relacional sustenta-se numa 
capacidade de trabalhar em conjunto, apoiada numa relação de confiança, respeito e num processo de aperfeiçoamento mútuo. Para cada um dos intervenientes, tendo em conta os seus distintos papéis, a referência ao contributo da relação supervisiva PPP-PM para o desenvolvimento profissional de ambos é frequentemente referida. No que se refere à dimensão técnico-instrumental é, no entanto, mais relevante a dimensão de avaliação do desempenho do que a de questionamento crítico.

Quanto ao segundo aspecto referido, a relação com os objetivos da formação (tal como definidos por Teresa Leite na secção anterior), os pôsteres remetem para os diferentes aspectos em que incidiu a formação: a construção do plano individual de trabalho e sua relação com o desenvolvimento profissional; a concepção e planeamento da ação de ensinar; a análise e discussão de situações de docência; a avaliação e regulação do desempenho profissional; a construção de registros e relatórios e seu potencial analítico e reflexivo (ALARCÃO; ROLDÃO, 2008). Relativamente ao seu papel na promoção de uma atitude crítica e reflexiva (REIS, 2008), nem todos os pôsteres analisados apresentam o mesmo grau de reflexividade ou de capacidade crítica relativamente às situações relatadas, no entanto, essa capacidade é ilustrada num conjunto de pôsteres. Esse resultado encontra-se sobretudo em episódios sustentados num uso sistemático e frequente da reflexão, contribuindo para o reforço da regulação e transformação das práticas profissionais.

No que se refere ao conhecimento profissional, destaca-se a presença de uma intencionalidade central na definição das situações descritas, que é sustentada pelas dimensões do conhecimento particular contempladas: o conhecimento do conteúdo, o conhecimento do currículo, o conhecimento didático, o conhecimento pedagógico e o conhecimento reflexivo (ROLDÃO, 2010). A mobilização do conhecimento científico que sustente a análise dos episódios apresentados nos pôsteres foi pouco expressiva. 0 recurso a referenciais científicos traduziu-se, na maioria dos casos analisados, num uso marcadamente formal, em grande medida como resposta à estrutura do pôster inicialmente proposto. Esses resultados indiciam uma prática profissional pouco alicerçada em conhecimentos de natureza científica, principalmente no que se refere a resultados de investigação em educação e quadros teóricos de referência, enquadradores das decisões e estratégias definidas. Tais resultados não são surpreendentes, confirmando o que trabalhos anteriores têm vindo a demonstrar (MARCELO, 2009; GALVÃO; REIS, 2002; ROLDÃO, 2009; NÓVOA, 2008).

Uma nota final sobre o contributo e articulação destes resultados e análise do processo relativo ao periodo probatório: se no início do programa se manifestaram resistências fortes, relativamente ao trabalho conjunto e à natureza da relação mentor/mentorado (reações recolhidas no primeiro seminário e nos dados apresentados neste dossiê, por Pedro Reis, Teresa Gonçalves e Luciana Mesquita) no momento finalizador do mesmo, com a apresentação dos pôsteres, tornou-se evidente a relevância do trabalho conjunto e do trabalho de supervisão no discurso fundamentador das propostas apresentadas nos pôste- 
res. Destaca-se assim a proximidade desses resultados com os apurados nos questionários analisados neste dossiê por Pedro Reis, Teresa Gonçalves e Luciana Mesquita, no que diz respeito à natureza da relação supervisiva, com priorização de uma relação entre pares, marcadamente horizontal, em detrimento de uma relação vertical (fortemente associada à relação estabelecida entre estagiário e orientador tal como sucede na formação inicial).

Retomando as dimensões teóricas e conceptuais que fundamentaram e orientaram a análise dos pôsteres, salienta-se que os dados resultantes ilustram o potencial analítico e reflexivo dos registros escritos no âmbito de processos supervisivos (ALARCÃO; ROLDÃO, 2008; DAY, 2001), na medida em que realçam a centralidade da reflexão no desempenho profissional, nomeadamente no que se refere ao diagnóstico do desempenho docente e ao planeamento de processos de melhoria de desempenho. No entanto, também revelam as fragilidades existentes relativamente à problematização do exercicio profissional eà autonomia de tomada de decisão na resolução de problemas. Aspectos esses que, por um lado, caracterizam a cultura profissional docente e, por outro, remetem para a necessidade de organização de processos de formação e supervisão que visem colmatar estas fragilidades.

A análise e discussão dos dados reforça a centralidade da dimensão do conhecimento profissional do professor, ao mesmo tempo que sustenta a necessidade de promover a sua produção no interior da profissão e da prática profissional, superando as fragilidades existentes (MARCELO, 2009; GALVÃO; REIS, 2002). Revela também um uso incipiente do conhecimento científico disponivel por parte dos docentes, no que diz respeito à forma como sustentam as suas decisões, fundamentam a sua prática e justificam a análise das situações vividas.

A análise dos pôsteres complementa os dados resultantes tanto da análise dos questionários apresentados por Pedro Reis, Teresa Gonçalves e Luciana Mesquita como da análise apresentada por Maria do Céu Roldão e Teresa Leite neste dossiê, relativamente à evolução da perspectiva sobre a supervisão ao longo do processo pelo par PM-PPP. Pretende ainda contribuir para pensar a forma como o processo de supervisão, entendido como uma ação orientada para o questionamento, a melhoria e a construção partilhada do conhecimento profissional e sustentada por um conjunto de dispositivos de diagnóstico, reflexão e (re)orientação com vista à melhoria da prática profissional, pode ser operacionalizado no sentido de constituir um instrumento de desenvolvimento profissional de professores em processo de indução.

\section{Referências}

ALARCÃO, I.; ROLDÃO, M. C. Supervisão: um contexto de desenvolvimento profissional dos professores. Mangualde: Edições Pedagogo, 2008.

ALARCÃO, I.; TAVARES, J. Supervisão da prática pedagógica: uma perspectiva de desenvolvimento e aprendizagem. 2. ed. Almedina: Coimbra, 2003. 
CAMPOS, J.; GONÇALVES, T. Supervisão e avaliação: construção de registros e relatórios. Aveiro: Universidade de Aveiro, 2010. (Coleção Situações de Formação n. 5).

DAY, C. Desenvolvimento profissional de professores. Os desafios da aprendizagem permanente. Porto: Porto Ed., 2001.

GALVÃO, C.; REIS, P. Um olhar sobre o conhecimento profissional dos professores: o estágio de Sofia. Revista de Educação, v. 11, n. 2, p. 165-178, 2002.

GONÇALVES, T. Investigar em Educação: fundamentos e dimensões da Investigação Qualitativa. In: ALVES, M. G.; AZEVEDO, N. R. (Eds.). Investigar em Educação desafios da construção de conhecimento e da formação de investigadores num campo multi-referenciado. Monte da Caparica: UIED/FCT/UNL, 2010.

LEITE, T. Planeamento e conceção da ação de ensinar. Aveiro: Universidade de Aveiro. Aveiro: Universidade de Aveiro, 2010. (Coleção Situações de Formação n. 2).

MARCELO, C. Desenvolvimento profissional docente: passado e futuro. Sísifo: revista de ciências da educação, Lisboa, n. 8, jan./abr. 2009.

NÓVOA, A. Percursos profissionais e aprendizagem ao longo da vida. In:

Desenvolvimento profissional de professores para a qualidade e para a equidade da aprendizagem ao longo da vida. Lisboa: Ministério da Educação, 2008.

REIS, P. As narrativas na formação de professores e na investigação em educação. Nuances: estudos sobre educação, v. 15/16, p. 17-34, 2008.

ROLDÃO, M. C. et al. 0 conhecimento profissional dos professores: especificidade, construção e uso da formação ao reconhecimento social. Revista Brasileira de Formação de Professores, Goiânia, v. 1, n. 2, set. 2009.

ROLDÃO, M. C. Construção de planos individuais de trabalho e desenvolvimento profissional. Aveiro: Universidade de Aveiro, 2010. (Coleção Situações de Formação n. 1).

ROLDÃO, M. C. Função docente: natureza e construção do conhecimento profissional. Revista Brasileira de Educação, Rio de Janeiro, v. 12, n. 34, p. 94-103, jan./abr. 2007.

Recebido em: 12/04/2012

Aceito para publicação em: 18/07/212 